\title{
QUANTIFICATION OF UNCERTAINTY IN SPATIAL MICROECONOMICS
}

\author{
George H. Carter*
}

Melvin Greenhut (1975) presented a theory of the firm in economic space in order to explain the oligopolistic interactions of firms over a landscape. The heart of this theory is explicit recognition of uncertainty as a determinant in entrepreneurial decisions. This paper presents a measure for quantifying uncertainty so that industry identification and entrepreneurial rewards can be given empirical content. One consequence of our new tool is that planners, regulators and economic researchers could possess a precise measure for the most indefinite of costs, profit. What is fair or excessive return in a world involving prices and market shares at different points is thereby determinable.

Quantification of spatial uncertainty also presents a means of addressing the question of efficiency in spatial markets. The excess of price over classical long-run average costs traditionally is viewed as unearned and, being a characteristic of spatial markets, is indicative of inefficient spatial resource allocation. Greenhut's identified return for spatial uncertainty is a return over and above classical long-run average costs, thus its measure provides for a more complete evaluation of spatial efficiency.

Section I reviews Greenhut's spatial microeconomic model in order to emphasize the importance of uncertainty and the need for its quantification. Section II presents an extension of the analysis of spatial competition which culminates in definition of the delivered price for a market. Then, Section III develops a quantified measure for the level of uncertainty incurred by a given firm in a specific market. A concluding statement is presented in Section IV.

\section{Greenhut's Spatial Model}

Figure 1 graphically describes the revenue and cost conditions confronting the firm operating in a spatial environment. ${ }^{1}$ The uncertainty intrinsic to decision-making in an oligopolistic world is a fixed cost, and this cost is additive to the traditional costs of the non-

*University of Southern Mississippi. The author is indebted to an anonymous referee for very helpful criticism. spatial firm in the Marshallian model. The existence of uncertainty led Professor Greenhut to develop a well-defined average cost curve. He adjusted the classical average cost curve (AC) upward by the applicable amount of fixed uncertainty in the industry. The adjusted average cost curves $\left[\mathrm{AC}_{\mathrm{fadj}}\right]$ of Figure 1 , therefore, graphically describe full spatial costs. Long-run entry/exit, consolidation/decentralization and dispersion/concentration provide the industry adjustments that achieve the static equilibrium described in Figure 1. In equilibrium, minimum $\mathrm{AC}$ is coterminous with a stable tangency between $\mathrm{AR}$ and $\mathrm{AC}_{\mathrm{fad} \cdot{ }^{2}}$ Optimum output $\left(\mathbf{Q}_{\mathrm{i}}{ }^{*}\right)$ thus coincides with minimum AC.

One may assume that there are $\eta$ firms in an industry, and that they conduct operations in a spatial, oligopolistic setting. Further, one may define $r$ as the total (cost) return required for the reigning level of uncertainty. Differentiation of $T R$, for the $i^{\text {th }}$ producer, yields $M R_{i}=p_{i}$ $+q_{i} p_{i}^{\prime}$, where $p_{i}^{\prime}=d p_{i} / d q_{i}\left[p_{i}=f\left(q_{i}\right)\right] .^{3}$ In general, $p_{i}^{\prime}<0 .{ }^{4} p_{i}$ therefore exceeds $M R_{i}$ by $\left|q_{i} p_{i}^{\prime}\right|$ $=q_{i}\left|p_{i}^{\prime}\right|$, as described in Figure 2. Superimposing the revenue curves on the applicable cost curves results in Figure 3. In long-run equilibrium, $\mathbf{A C}_{\text {fadj }}$ exceeds classical $\mathbf{A C}$ by $\mathbf{Q}_{i}^{*}\left|p_{i}^{\prime}\right|$, which is the average return per unit of output for the fixed uncertainty cost $\left(r / q_{i}\right)$. The total return for uncertainty, $r$, equals the average return for uncertainty, multiplied by quantity. Consequently, the fixed adjusted average cost

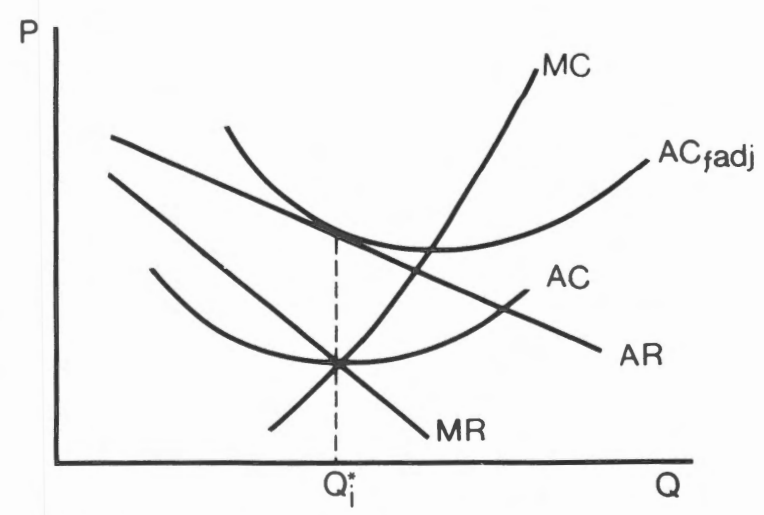

Figure 1. Spatial Oligopolistic Equilibrium 


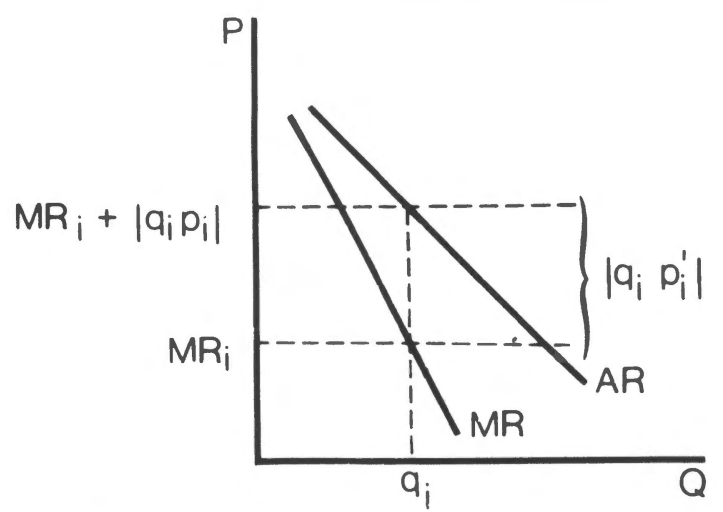

Figure 2. AR/MR Difference

curve for the $\mathrm{i}^{\text {th }}$ producer is:

$$
\mathrm{AC}_{\text {fadj }}=\mathrm{AC}+\left(\mathrm{r} / \mathrm{q}_{\mathrm{i}}\right)=\mathrm{AC}+\left\{\left[\left(\mathrm{Q}_{\mathrm{i}}^{*}\right)^{2}\left|\mathrm{p}_{\mathrm{i}}^{\prime}\right|\right] / \mathrm{q}_{\mathrm{i}}\right\}
$$

where

$$
\mathrm{r}=\left[\left(\mathbf{Q}_{\mathrm{i}}^{*}\right)^{2}\left|\mathbf{p}_{\mathrm{i}}^{\prime}\right|\right]
$$

A characteristic of these computations is that uncertainty and its return depend on $\left|\mathbf{p}_{\mathrm{i}}^{\prime}\right|$. If demand is linear, and of course negative sloped, $p_{i}^{\prime}$ is not only negative, but is a negative constant, regardless of $q_{i}$. Since the absolute value of $p_{i}^{\prime}$ is central to this analysis, a special name is assigned to it, "the coefficient of uncertainty." The total uncertainty incurred by a firm equals $\left(Q_{i}^{*}\right)^{2}\left|p_{i}^{\prime}\right|$ where minimum AC defines $Q_{i}^{*}$. The "slope of AR" (coefficient of uncertainty) component of $\left(Q_{i}^{*}\right)^{2}\left|p_{i}^{\prime}\right|$ uniquely indicates the relative magnitude of total uncertainty. This point is the central thesis of our paper.

When uncertainty is altered, the size and number of firms change and the position of AR shifts. In comparative static analysis, a greater (lesser) degree of uncertainty means that the coefficient of uncertainty must increase (decrease). This conclusion follows because AR

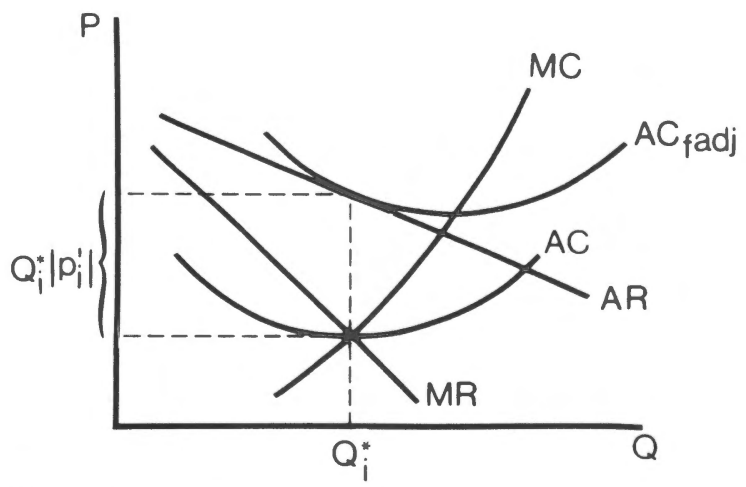

Figure 3. Average Uncertainty must be steeper (flatter) in order to provide a tangency with the higher (lower) $\mathrm{AC}_{\text {fadj }}$ curve. The definition of $\mathrm{AC}_{\text {fadj }}$ at equilibrium illustrates this assertion:

$$
\mathrm{AC}_{\text {fadj }}=\mathbf{A C}+\left(\mathbf{r} / \mathbf{Q}_{\mathrm{i}}^{*}\right)=\mathbf{A C}+\mathbf{Q}_{\mathbf{i}}^{*}\left|\mathbf{p}_{\mathbf{i}}^{\prime}\right|
$$

Classical AC and its minimum point (hence associated with output $\mathrm{Q}_{\mathrm{i}}^{*}$ ) do not change when the level of uncertainty is varied. $\mathrm{AC}_{\text {fadj }}$ therefore varies directly with $\left|p_{i}^{\prime}\right|{ }^{5}$

\section{Delivered Price}

A technique illustrated by Greenhut and Ohta generalized the Cournot model.$^{6}$ For this generalization, assume (1) n local submarkets or buying points scattered over a land surface, (2) $\mathrm{m}$ sellers also dispersed over the land surface, (3) homogeneous products, and (4) Cournot type of competition, i.e., each firm considers its rival firms' supply to be fixed at any given buying point.

The distribution of markets and sellers conceived of herein is illustrated in Figure 4 for the case of two sellers and three buying points, i.e., $m=2$ and $n=3$. Distance costs (in terms of freight rates) from firm $A$ to market points $a, b$, and $c$ are represented by $T_{11}, T_{12}, T_{13}$, and costs of distance from firm $B$ to the same market points are represented by $T_{21}, T_{22}, T_{23}$. Average cost of transportation to market point a is defined as the average of all firms' freight costs to that buying point, i.e., $\left(\mathrm{T}_{11}+\mathrm{T}_{21}\right) / 2$. Correspondingly, average freight costs to market points $b$ and $c$ are respectively $\left(T_{12}+T_{22}\right) / 2$ and $\left(\mathrm{T}_{13}+\mathrm{T}_{23}\right) / 2$.

Define the local demand function at market point $j$ as:

$$
p_{j}=f_{j}\left(q_{\cdot j}\right), j=1,2, \ldots, n
$$

where $q_{\cdot j}$ represents the quantity demanded at $\mathrm{p}_{\mathrm{j}}$ in market $\mathrm{j}$. This quantity is to be distin-

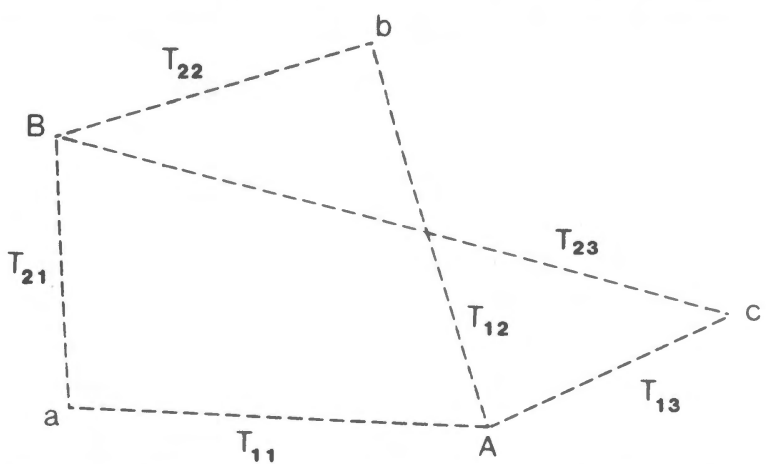

Figure 4. Market Points and Firm Sites Distributed Over Economic Space 
guished from $q_{i}$, which stands for the quantity produced by the $i^{\text {th }}$ seller. These variables consist of the partial aggregates of quantity supplied by each of the $i$ firms selling to market point $j$, as represented by $q_{i j}$. Thus we have

$$
\begin{aligned}
& q_{\cdot j}=\sum^{m_{i=1}} q_{i j}, j=1,2, \ldots, n ; \\
& q_{i}=\sum^{n}{ }_{j=1} q_{i j}, i=1,2, \ldots, m .
\end{aligned}
$$

Equation (2) establishes the equilibrium condition for the quantity demanded at point $j$ and the quantity supplied by all $\mathrm{m}$ firms; (3) states that the quantity produced by the $\mathrm{i}^{\text {th }}$ firm must equal the total quantity shipped by this firm to its $\mathrm{n}$ market points.

Profits for the $i^{\text {th }}$ firm are definable as the firm's total revenues on sales to $\mathrm{n}$ market points less total production and transportation costs:

(4) $\pi_{i}=\sum^{n_{j=1}} p_{j} q_{i j}-K_{i}-\sum^{n_{j=1}} T_{i j} q_{i j}, i=1,2$, ..., $\mathrm{m}$,

where $K_{i}$ stands for the cost of production as a function of $q_{i}$ (which is independent of total $q_{i j}$ ) while $T_{i j}$ stands for the freight rate (per unit quantity) applicable to the distance from the firm's site i to buying sitej. The problem for firm $i$ is to maximize $\pi_{i}$ subject to Cournot type of competition. Thus (5) below applies

(5) $\left(\partial \pi_{\mathrm{i}}\right) /\left(\partial \mathrm{q}_{\mathrm{ij}}\right)=\mathrm{p}_{\mathrm{j}}+\mathbf{f}_{\mathrm{j}}^{\prime}\left(\mathrm{q}_{\cdot \mathrm{j}}\right) \mathrm{q}_{\mathrm{ij}}-\mathbf{k}_{\mathrm{i}}-\mathrm{T}_{\mathrm{ij}}=0$; $\forall \mathrm{i}, \mathrm{j} ; \mathbf{k}_{\mathrm{i}}=\left(\mathrm{dK}_{\mathrm{i}}\right) /\left(\mathrm{dq}_{\mathrm{i}}\right)$

where $k_{i}$ is firm i's marginal cost of production. ${ }^{7}$

In Walrásian style, the number of equations and unknown variables may be counted over equations (1) to (5). We find $n$ equations in (1), $n$ in (2), $m$ in (3), $m$ in (4) and $m n$ in (5), i.e., 2 $(\mathrm{m}+\mathrm{n})+\mathrm{mn}$ in total; in turn, there are $\mathrm{n}$ variables for $\mathrm{p}_{\mathrm{j}}, \mathrm{n}$ for $\mathrm{q}_{\mathrm{j}_{\mathrm{j}}}, \mathrm{m}$ for $\mathrm{q}_{\mathrm{i}}, \mathrm{m}$ for $\pi_{\mathrm{i}}$, and $\mathrm{mn}$ for $q_{i j}$, i.e., the same $2(m+n)+m n$ in total. Thus we may conclude that the system of equations can be solved for all unknown variables.

Operationally meaningful results require, however, summing (5) over all i to obtain

(6) $\mathrm{mp}_{\mathrm{j}}+\mathrm{f}_{\mathrm{j}}^{\prime}\left(\mathrm{q}_{\cdot \mathrm{j}}\right) \mathrm{q}_{\cdot \mathrm{j}}-\sum^{\mathrm{m}_{\mathrm{i}=1}} \mathbf{k}_{\mathrm{i}}-\sum^{\mathrm{m}_{\mathrm{i}=1}} \mathrm{~T}_{\mathrm{ij}}=0, \forall \mathrm{j}$.

Dividing both sides of (6) by $\mathrm{m}$ yields

$$
p_{j}\left[1-\left(1 / m_{j}\right)\right]-\bar{k}-\bar{T}_{j}=0, \forall j \text {. }
$$

where $e_{j}$ stands for the market elasticity of demand at buying point $\mathrm{j}$, and $\overline{\mathrm{k}}$ and $\overline{\mathrm{T}}_{\mathrm{j}}$ stand respectively for the average marginal costs of production and transportation, i.e., $\bar{k}=(1 / \mathrm{m})$ $\Sigma_{\mathrm{i}} \mathrm{k}_{\mathrm{i}}$ and $\overline{\mathrm{T}}_{\mathrm{j}}=(1 / \mathrm{m}) \sum_{\mathrm{i}} \mathrm{T}_{\mathrm{ij}}$. The delivered price at market point $j$ is, therefore, fully determined by

$$
p_{j}=\frac{\bar{k}+\overline{T_{j}}}{\left[1-\left(1 / \mathrm{me}_{j}\right)\right]} \quad, \forall j .
$$

\section{Uncertainty Quantification}

In order to simplify this presentation, analysis concentrates on a single market, the $\mathrm{j}^{\text {th }}$, and the " $j$ " subscripts are ignored. Equation (7), the delivered price to the $\mathrm{j}^{\text {th }}$ market, is therefore rewritten as

$$
\mathbf{p}=\frac{\left[(1 / \mathrm{m}) \Sigma_{\mathrm{i}} \mathbf{k}_{\mathrm{i}}\right]+\left[(1 / \mathrm{m}) \Sigma_{\mathrm{i}} \mathbf{T}_{\mathrm{i}}\right]}{[1-(1 / \mathrm{me})]}
$$

Suppose we recognize now that the market demand elasticity, e, is the empirical unknown in the expression. Consequently, our rearrangement of terms yields:

$$
e=\frac{p}{m\left[p-(1 / m)\left(\sum_{i} k_{i}\right)-(1 / m)\left(\Sigma_{i} T_{i}\right)\right]}
$$

The next step is to obtain the elasticity of demand for the $i^{\text {th }}$ firm, $e_{i}$, from market demand elasticity. It is established ${ }^{8}$ that individual demand in an open entry/exit Cournot market, is parallel to market demand. Further, if there are $\mathrm{m}$ competitive producers dividing market demand, then each supplies $\alpha_{i}$ times market quantity supplied $\left(\sum_{\mathrm{i}} \alpha_{\mathrm{i}}=1\right)$. Market quantity supplied is $[\mathrm{m} /(\mathrm{m}+1)]$ of the quantity that a perfectly competitive arrangement of the market would supply, and $\alpha_{i}$ is the $i^{\text {th }}$ producer's share of the $j^{\text {th }}$ market. This share equals the $j^{\text {th }}$ market total revenue of the $i^{\text {th }}$ firm divided by the aggregate $j^{\text {th }}$ market total revenue received by all $\mathrm{m}$ firms.

We know that $e=(d q / d p)(p / q)$ and $e_{i}=\left(d q_{i} /\right.$ $\mathrm{dp})\left(\mathrm{p} / \mathrm{q}_{\mathrm{i}}\right)$. A single price must reign in the $\mathrm{j}^{\text {th }}$ market since the firms compete and, as noted, market and individual demands are parallel when the market is non-collusive. Therefore, $(\mathrm{dq} / \mathrm{dp})=\left(\mathrm{dq}_{\mathrm{i}} / \mathrm{dp}\right)$. The only deviation between $e$ and $e_{i}$ is between the market quantity supplied, q, and the individual quantity supplied, $\mathrm{q}_{\mathrm{i}} \cdot \alpha_{\mathrm{i}} \mathrm{q}=\mathrm{q}_{\mathrm{i}}$, so

$$
e_{i}=e / \alpha_{i}
$$

The coefficient of uncertainty is now defined in terms of available data:

$$
\mathrm{e}_{\mathrm{i}}=\left|\left(\mathrm{d} \mathrm{Q}_{\mathrm{i}}^{*} / \mathrm{dp}_{\mathrm{i}}\right)\left(\mathrm{p}_{\mathrm{i}} / \mathrm{Q}_{\mathrm{i}}^{*}\right)\right|=\left(1 /\left|\mathrm{p}_{\mathrm{i}}^{\prime}\right|\right)\left(\mathrm{p}_{\mathrm{i}} / \mathrm{Q}_{\mathrm{i}}^{*}\right)=\mathrm{e} / \alpha_{\mathrm{i}}
$$
and

$\left|p_{i}^{\prime}\right|=\left[\left(\alpha_{i} m\right) / Q^{*}\right]\left[p-(1 / m)\left(\sum_{i} k_{i}\right)-(1 / m)\left(\sum_{i} T_{i}\right)\right]$

The components of this expression, to review, are:

$\left|p^{\prime}{ }_{i}\right|$ is the slope of $A R$ and $A_{\text {fadj }}$ at equilibrium output $Q_{i}^{*}$. $\left|p_{i}^{\prime}\right|$ has been shown to be a unique coefficient for measuring the level of uncer- 
tainty that the $\mathrm{i}^{\text {th }}$ firm incurs in a specific market, the $j^{\text {th }}$ market. $\alpha_{i}$ stands for the market share of the $i^{\text {th }}$ firm, and $m$ is the number of firms servicing the $j^{\text {th }}$ market. Finally, the costs incurred by the $\mathrm{i}^{\text {th }}$ firm are $\mathrm{k}_{\mathrm{i}}$, the marginal production cost, and $\mathrm{T}_{\mathrm{i}}$, the cost of transporting the product to the $\mathrm{j}^{\text {th }}$ market.

\section{Conclusion}

This paper has developed a coefficient of uncertainty which indicates the relative uncertainty under which a given firm operates. The various spatial cost curves can be explicitly defined by using our cardinal measure of uncertainty. Together, our tools provide the planner with the means for realistic pricing policies which adequately reward all factors of production.

The coefficient of uncertainty also provides a means of addressing the question of efficiency in spatial equilibrium. It is believed that spatial equilibrium is inefficient because positive long-run economic profits may accrue. Greenhut contends that spatial equilibrium is efficient and what appears to be long-run economic profit is really the entrepreneur's opportunity cost return to spatial uncertainty, a return which is earned. In fact, he explains that the return to uncertainty is minimized by the competitive activities of entry/exit and plant rationalization. The quantified measure of uncertainty allows further examination of this issue.

\section{FOOTNOTES}

'See Greenhut (1974, Chapter 5) for an in-depth discussion concerning this description of the firm.

${ }^{2}$ Greenhut (1974, pages 86-98) develops completely the adjustments which generate this specific tangency, while Ohta (1976) formalizes the necessary and sufficient conditions for the equilibrium. Ohta further presents this conception of the firm as another, but more comprehensive, refutation of the Robinson-Chamberlin excess capacity theorem of imperfect competition. Demsetz (1959) and Dewey (1958) provided contributions which preceded Ohta on this question. Ohta (1977) further develops this point.

${ }^{3}$ The analysis of this paper is in terms of a linear AR curve. Footnote 5 addresses the effects of a more generally described AR curve in order to show that this working assumption does not affect the validity of the conclusions.

${ }^{4} p_{i}^{\prime}=0$ under conditions of perfect competition and $p_{i}^{\prime}>$ 0 for Giffen goods (a case we assume away as of negligible importance).

5The text has assumed a linear demand for convenience but the conclusions are not altered when demand is more generally defined. Ohta (1976) proved, for the general case, that spatial equilibrium is characterized by tangency of AR and $\mathrm{AC}_{\text {fadj }}$ at the output which corresponds with minimum classical $\mathrm{AC}$. This equality of the $\mathrm{AR}$ and $\mathrm{AC}_{\text {fadj }}$ slopes at $\mathrm{Q}^{*}$ is precisely the linear analysis coefficient of uncertainty. The only complication which curvilinear AR introduces is that this slope will have to be evaluated by "plugging in" $Q_{i}^{*}$ whereas $\left|p_{i}^{\prime}\right|$ is a constant regardless of $q_{i}$ in the straight-line case. Aside from this "inconvenience," the coefficient of uncertainty is measured by the equilibrium tangency slope and its interpretation is identical under either type of demand. One qualification is necessary, however. When AR is considered to have a non-constant first derivative, stability of spatial equilibrium requires that a convex to the origin $\mathrm{AR}$ be of less convexity than $\mathrm{AC}_{\mathrm{fadj}}$ at the point of tangency [i.e., at outputs less than $\mathrm{Q}_{i}^{*},\left|\mathrm{~d}(\mathrm{AR}) / \mathrm{dq}_{\mathrm{i}}\right|<$ $\left|\mathrm{d}\left(\mathrm{AC}_{\text {fadj }}\right) / \mathrm{dq}_{\mathrm{i}}\right|$ and for $\mathrm{q}_{\mathrm{i}}>\mathbf{Q}_{\mathrm{i}}^{*},\left|\mathrm{~d}(\mathrm{AR}) / \mathrm{dq}_{\mathrm{i}}\right|>\left|\mathrm{d}\left(\mathrm{AC}_{\mathrm{fadj}}\right) / \mathrm{dq}_{\mathrm{i}}\right|$; manifestly at $\left.q_{i}=Q_{i}^{*},\left|d(A R) / d q_{i}\right|=\left|d\left(A_{\text {fadj }_{j}}\right) / d q_{i}\right|\right]$. Greenhut and Ohta (1975) have shown that a spatial firm's aggregate demand curve will be convex, regardless of the shape of the individual consumer's demand.

${ }^{6}$ Greenhut and Ohta (1975) present this analysis in Chapter 8, Appendix I. Greenhut and Greenhut (1975) also describe this analysis in Section III, 3. The empirical findings of Greenhut, Greenhut and $\mathrm{Li}$ (1980) justify the use of a price discrimination model in developing a measure of uncertainty. We present the analysis in order to lay clearly the basis of our quantification of uncertainty.

${ }^{7}$ The subject equation requires the assumption $p_{j} \geqslant k_{i}+T_{i j}$ for all $i$ and $j$. Without this condition, the summation takes place only up to $m_{j}<m$, where $m_{j}$ represents the number of firms selling to market point $\mathrm{j}$. This $\mathrm{m}_{\mathrm{j}}$ is determined by the number of firms whose particular marginal revenue in that market equals the firm's marginal costs, $k_{i}+T_{i j}$ -

${ }^{8}$ Greenhut (1956, Section 3.1, n. 45) and Greenhut (1974, pages 154-157) provide formal treatment of this Cournot conclusion.

\section{REFERENCES}

Demsetz, H. "The Nature of Equilibrium in Monopolistic Competition." Journal of Political Economy, February 1959, 21-30.

Dewey, D. "Imperfect Competition No Bar to Efficient Production." Journal of Political Economy, February 1958, 24-33.

Greenhut, John G. and M. L. Greenhut. "Spatial Price Discrimination, Competition and Locational Effects." Economica, November 1975, 401-419.

Greenhut, John G., M. L. Greenhut and Sheng-Yung Li. "Spatial Pricing Patterns in the United States." Quarterly Journal of Economics, March 1980, 329-350.

Greenhut, M. L. and H. Ohta. Theory of Spatial Prices and Market Areas. Durham, N.C.: Duke University Press, 1975.

Greenhut, M. L. "A Theoretical Mapping from Perfect Competition to Imperfect Competition." Southern Economic Journal, October 1975, 177-192.

Greenhut, M. L. A Theory of the Firm in Economic Space, 2nd printing. Austin, Texas: Lone Star Publishers, 1974.

Greenhut, M. L. Plant Location in Theory and in Practise. Chapel Hill: The University of North Carolina Press, 1956.

Otha, H. "On Efficiency of Production under Conditions of Imperfect Competition." Southern Economic Journal, October 1976, 1124-1135.

Ohta, H. "On the Excess Capacity Controversy." Economic Inquiry, April, 1977, 153-175. 